\title{
REPRESENTING MASS VIOLENCE - CONFLICTING RESPONSES TO HUMAN RIGHTS VIOLATIONS IN DARFUR BY JOACHIM J. SAVELSBERG (2015, Oakland, University of California Press)
}

TONI PRANIĆl

The book Representing Mass Violence by Joachim J. Savelsberg, professor of sociology and law, about representations of violence in Rwanda, is a very thoughtfully conceptualised and written work. Though the theme of media analysis may sound limited, the way in which this research was planned, carried out and interpreted demonstrates a high level of theoretical and empirical craft. Savelsberg, along with his team, analysed 3387 news reports and conducted interviews. The outcome is this book, divided into 4 parts: Justice versus Impunity; Aid versus Justice: The Humanitarian field; Peace versus Justice: The Diplomatic Field; and Mediating Competing Representations: The Journalistic Field. Before the first part, the author gives a brief introduction to the research. He starts with a famous quote by W.I. Thomas, "If men define situations as real, they are real in their consequences". This statement represents his guiding line in exploring the violence in Darfur in the first decade of the $21^{\text {st }}$ century, which he does through perspectives of human rights, criminal law, humanitarianism, and diplomacy. The conflict was widely covered in the media but the coverage was influenced by various sources, which alone does not explain the variation in the representations of violence in Darfur. The author states that his main discovery is a response to the question "How do global actors, national contexts, and distinct fields interact to create at times conflicting social constructions of reality?', Among the important components of the research are discussions of the criminalization of human rights violations, the embeddedness of actors in competing fields (of criminal justice, diplomacy and humanitarian aid), the role of the media, interactions between global and national actors, and the consequence of knowledge on responses to violence.

1 Toni Pranić is a Ph.D. student at the Corvinus University of Budapest, and teaching assistant at the Faculty of Law Osijek; e-mail: tpranic@pravos.hr 
Sampling was undertaken in two North American Countries (the U.S. and Canada) and six European ones (Austria, France, Germany, Ireland, the UK and Switzerland). Articles, editorials and op-ed pieces that were published between January 1, 2003 and May 30, 2010 were collected. Coding employed 179 variables gathered under a few crucial themes: the degree of acknowledgment of the situation, the actors involved, perceived causes, the frame for interpreting the violence, and references to past atrocities.

Over the last two decades there has been an increase in individual criminal accountability in human rights violations, a situation known as the justice cascade. The first chapter, Setting the stage, deals with changes in judicial interventions in international law. The basic premises of the justice cascade are deterrence through the threat of punishment, and cultural intervention into judiciary-delegitimizing violence narratives. Savelsberg draws heavily on the much-debated work of Kathryn Sikkink and her depictions of change in the area of human rights. The violence in Darfur started in the summer of 2003, but it was only during the second wave of killings that the West began to take it seriously, from the initial genocide alert of the United States Holocaust Memorial, through the U.N., the United Nations Security Council and finally, the International Criminal Court. The cascade ended with the latter issuing warrants for arrest. Another important implication of this process is the already mentioned delegitimizing function which provides a means of deterrence. But the approach to Darfur was mostly viewed through the prism of criminal violence, which concentrated upon a few key individuals and omitted the structural context, together with organizational issues. Although there have been no convictions so far, through this approach the Court provided the interpretational frame.

The chapter Human Rights Field and Amnesty International deals with the role of international nongovernmental organizations. Their role in representing violence to the public has increased during the last few decades, and their increasing importance has been accompanied by a greater level of respect within countries. INGO's are often parts of larger transnational advocacy networks, and are first responders when violent conflicts occur. Having this role and privilege, they also posses the ability to influence the frame of representation and reaction. Amnesty International played a core role in terms of the information which was transmitted about the violence in Darfur. Through interviews with their employees, a simple overview of perceived goals was identified. This showed, not surprisingly, that the main goal the organisation supported was achieving justice through the prevention of impunity. In the eyes of their employees, responsibility should be laid on the government which had politicized old conflicts. Respondents were more apt to label perpetrators than label crimes during juridical proceedings. This conforms to the guidelines issued by their 
management, the International Secretariat. This situation represents the bottom of the judicial cascade and serves as a basic network through which situations are mediated to other international and national actors. While the organisation is undertaking humanitarian work, they follow a certain policy which treats upholding justice as the primary task. They suppose that the achievement of this goal is most important because it enables progress in terms of establishing peace and assisting victims to survive.

Another important element of the justice cascade are state actors, as explained in the chapter American Mobilization and the Justice Cascade. It was organizations within the U.S. that initially alerted the wider public to the situation in Darfur. From the United States Holocaust Memorial Museum coverage spread through international institutions and media. American media were more prone to cover the different forms of victimization. They also framed the events as a crime more often than other countries. Among the interesting practices was the bridging of events. In connection to earlier occurrences of violence, the U.S. media bridged events to genocide and holocaust more often than in other media. The author argues that the reason for this can be identified as the mediation of events by civil society movements and representations, which in the US are enhanced by a competitive media market. This arrangement of social actors created significant pressure on the US government to take action, although it did not ratify the Rome statute. Besides their strong rhetoric and close cooperation with organizations that provided assistance to Darfur, the US government avoided direct involvement due to their ongoing experience with war. But due to its previous experience and culture, it was most forward in categorising the Darfur violence as genocide. This example shows the influence of the field in the representation of events.

The second part of the book begins with a depiction of aid-oriented INGOs in a chapter entitled The Humanitarian Aid Field and Doctors Without Borders. Doctors Without Borders was established in 1971 by some former members of the International Committee of the Red Cross. Besides providing medical aid to victims, the organisation is distinguished by its denunciation of silence and willingness to act as witness. In Darfur, Doctors Without Borders was the first organisation to challenge official Sudanese claims about the massacres. This later caused a backlash since the NGO was expelled from Sudan in 2009, the stated reason being that they had not adhered to the principle of neutrality. During all the interviews, all the employees stated that the delivery of aid was the primary goal for Darfur. There was some tension within the organisation due to its dual role of temiognage (bearing witness) and providing aid. This field constellation accounted for some interesting responses in regard to representations. The interviewees demonstrated caution and reluctance to categorize the violence due to its possible instrumentalisation for political purposes. There is an obvious 
ambivalence in their coping strategy as concerns the issues of suffering and crime, which is probably connected to the dual role the organisation plays. Among other things, in apportioning responsibility employees went further in terms of contextualising the situation. Though they did blame the government, they also contextualised it into a larger process, natural and cultural. Another important consideration for the organisation is that main actor in the field of providing aid in the given country is the government. This fact may explain why there is a reluctance to categorise crime and violence, since their primary role as aid givers is dependent upon how the host country perceives the organisation. Therefore, the features that the NGO is most likely to highlight are those which can safely be addressed. This fact should be kept in mind when the author compares representational scripts from the field of human rights and humanitarian aid.

The fifth chapter, Humanitarian Complex and Challenges to the Justice Cascade, questions the role of governmental aid policies using the example of Ireland. In this case, humanitarian policy is not just something that stems from government policy, but it is a product of wider social climate. This is what Savelsberg called the "influence of collective memory", which in the Irish case dates from the nineteenth century Great Famine. But the analysis in the chapter brings up another consideration - that government aid policy meets the same problems as other humanitarian organisations, since they both seek to influence the policies (and their outcomes) of recipient countries. And, as with humanitarian organisations, governments have views about how violence should be represented. There is also a relationship between the latter and the country context. The more a country is invested in aid programmes, the more the media will use a humanitarian narrative in its reporting.

The third part of the book begins with Diplomatic Representations of Mass Violence. The diplomatic field is most similar to that of the humanitarian aid arena, but differs from the judicial field. Diplomatic agencies typically strongly identify with their mission. Their accounts of violence in the case of Darfur were directed towards the government as a responsible agent; there was also a focus on helping the victims. This narrative focuses on the long-term process of developing political responsibility, and through this, dealing with the structural causes of conflict. The next chapter, The Diplomatic Field in National Contexts, provides a comparative analysis of diplomatic fields. Similarities and differences arise for various reasons. The example of Austria shows that although the country could be seen as politically similar to Ireland and Switzerland, diplomatic activities were guided by a different set of principles that were influenced by their close ties to the Arab world. For the former colonial countries, France and the United Kingdom, the situation was similar. Diplomats were more cautious about labelling violence and responsibility; they mostly attributed events to natural and political 
conditions. Perhaps the most ambivalent context concerns Germany. While one would assume that the legacy of the Third Reich and the attendant holocaust would make decision-makers sensitive and active in reacting to mass violence, the legacy also imposes significant constraints. The word genocide carries great weight, and constrains action. In the case of Germany, cultural trauma acts as an inhibitor. According to this perspective, the country's status matters: from Swiss historical neutrality to French colonial legacy. The context shows events and their depictions to be affected by a political and cultural legacy that is affected by external historical roles, as well as an internally developed culture.

The last part of the book deals with media representations. Drawing from Bourdieu's views of journalism, in Rules of the Journalistic Game, Autonomy, and the Habitus of Africa Correspondents, Savelsberg addresses the marginality of reporting about Africa. The nature of events in Africa requires a specific set of reporting characteristics. But coverage of Africa is also situated in a global network of media actors. Therefore the majority of journalists who were interviewed stated that placing Africa in this frame was their primary task. Some mentioned that Africa is usually the first location that young reporters are assigned to. Most of the journalists were middle-class and had some knowledge of Africa (mostly biographical). Since they are far from their organisations, they rely on other colleagues in the field. They have significant autonomy, but it is not at all absolute. The rules of their games are also influenced by their organizations to some extent.

The last chapter, Patterns of Reporting, presents an analysis of media coverage of the same events. The number of reports created in different countries follows the same trend and peaks at around the same time. Its intensity varies for reasons related to the national context. Germany presented most coverage of the violence in Darfur, a fact which the author explains through the country's historical legacy and cultural trauma. But at the same time, this coverage was not accompanied by intense activity or representation. The U.S. had the second largest amount of coverage, and was significantly influenced by various civil society organizations, but most influence came from religious organizations. One interesting situation and explanation of content concerns Ireland. This country covered events in only one newspaper, but the coverage was significant in terms of quantity. Irish involvement was also much greater than this fact would indicate. Media coverage in general did not always correspond to real events. Representations also varied according to the situation in the field. An intriguing example of this is the decrease in humanitarian representations after 2007 caused by the expulsion of Doctors Without Borders. This also showed that humanitarian emergencies are short-lived in terms of media coverage since they can lose significance quickly. 
The author draws several conclusions. Reactions by the international community were propelled by the justice cascade, while they also constituted part of cascade. This cascade was mostly channelled through transnational activist networks. Mass violence was attributed to a small number of individuals, and structural conditions were ignored in the judicial field. From the human rights perspective, the influence of globalising forces is evident. Another field of coverage represented aid NGOs. Since their role is twofold, their narratives are cautious and they address situations that can be addressed by their programmes. The field of aid also displays characteristic global and global-national tensions. The diplomatic field narrative focuses on long-term solutions and the structural causes of conflict, while avoiding naming responsible actors. Journalists are semiautonomous actors, dependent on their external sources of information.

Throughout this book the importance of the justice cascade is made evident. What is more important is the influence of the national context in the cascade. This can have positive, negative or mutual effects (as in the case of Germany). But the unavoidable fact is that the justice cascade (although no arrests have been made) acted to deter violence. The second-level theoretical contribution of the research relates to the importance of the construction of representations within certain fields. It shows that along with human rights, aid and the diplomatic sector, representations are simultaneously made at the national and international level. This multiplicity of fields highlights the problems which exist for the different actors or organizations within them. From cultural trauma to the nature of the governments in countries which receive aid, the fields both provide incentives to action and also constrain it. Knowledge and action are situated within them, and they are, as Savelsberg puts it, interpenetrable. 